\title{
O PROJETO PARLAMENTO JOVEM DO TRE/PR: RELATO DE EXPERIÊNCIA DO MUNICÍPIO DE JACAREZINHO - PARANÁ
}

\author{
Paulo Roberto Braga Junior ${ }^{1}$ \\ Ana Paula Pavanini Navas ${ }^{2}$
}

\section{Resumo:}

O artigo trata do Projeto Parlamento Jovem, realizado pelo Tribunal Regional Eleitoral do Paraná em parceria com a Câmara Municipal do Município de Jacarezinho. A pesquisa bibliográfica, documental e de campo realizada neste trabalho traz a importância da participação política e democrática dos adolescentes em sua comunidade, por meio de ações educacionais, visitas guiadas, explanação de conceitos básicos sobre Poderes Legislativo, Executivo e Judiciário. O Projeto culmina na promoção de eleição de vereadores mirins/jovens, em processo eleitoral nas instituições de ensino. Mostra a percepção dos alunos participantes quanto ao papel que lhes cabem em sua comunidade, enquanto inseridos na sociedade.

Palavras-chave: Parlamento Jovem; Participação Política; Democracia; Vereadores Mirins/Jovens.

\section{THE YONG PARLIAMENT PROJECT FRON TRE/PR: A REPORT OF THE EXPERIENCE IN THE CITY OF JACAREZINHO - PARANÁ}

\begin{abstract}
:
The article deals with the Youth Parliament Project, carried out by the Paraná Regional Electoral Court in partnership with the Municipality of Jacarezinho. Bibliographic, documentary and field research carried out in this work brings the importance of the political and democratic participation of adolescents in their community, through educational actions, as guided tours, explanation of basic concepts about the Legislative, Executive and Judiciary. The project culminates in the promotion of the election of junior/young councilors, in the electoral process in educational institutions. It shows the perception of the participating students regarding their role in their community while inserted in society.
\end{abstract}

Keywords: Young Parliament; Political Participation; Democracy; Junior/Young Councilors.

\footnotetext{
${ }^{1}$ Bacharel em Direito. Especialista em Educação e Sociedade pelo Instituto Federal do Paraná - IFPR, e em Gestão Pública pela Universidade Estadual de Ponta Grossa - UEPG. Mestrando em Ciência Jurídica pela Universidade Estadual do Norte do Paraná - UENP. Atua na 24a Zona Eleitoral do Tribunal Regional Eleitoral do Paraná - TRE/PR. E-mail: pbragajunior @ hotmail.com

${ }^{2}$ Bacharel em Direito. Especialista em Direito Tributário e em Direito Constitucional pela UNISUL . Mestre em Ciências Jurídicas pela Universidade Estadual do Norte do Paraná - UENP. Analista Judiciária do Tribunal Regional Eleitoral do Paraná - TRE/PR. E-mail: anavas@tre-pr.jus.br
} 


\section{INTRODUÇÃO}

O Projeto Parlamento Jovem, do Tribunal Regional Eleitoral do Paraná - TRE/PR, tem como objetivo proporcionar a vivência do processo político e democrático a estudantes da educação básica (ensino fundamental e médio). Por meio dele, oportuniza-se a participação de estudantes em um processo eleitoral simulado, que inclui: filiação partidária, convenção partidária com escolha de candidatos, propaganda eleitoral, votação, diplomação, posse e exercício de mandato como vereador mirim/jovem.

Considerando não só a importância de que os estudantes aprendam sobre formas de participação política, democracia representativa e a divisão dos poderes do Estado, o projeto também proporciona aos participantes o exercício de habilidades de comunicação, argumentação, elaboração de projetos e requerimentos, valorização do consenso e do bem comum.

Neste sentido, a finalidade deste trabalho é promover reflexões acerca da importância do projeto Parlamento Jovem do TRE/PR para o letramento político de estudantes e verificar como ele pode contribuir para a mudança e a construção de novos olhares e atitudes quanto à vida política em sociedade.

A pesquisa está assim estruturada: na primeira parte propõe-se uma caracterização das contribuições da educação para a formação política, apresentam-se conceitos de educação para a democracia e letramento político. Na segunda parte, explicitam-se os objetivos e as dimensões do Projeto Parlamento Jovem do TRE/PR. Na terceira parte, verifica-se a experiência da implementação do projeto no município de Jacarezinho - Paraná, no primeiro semestre de 2019.

Para atender às finalidades destacadas, elegeram-se como procedimentos técnicos a pesquisa bibliográfica, documental e de campo. Assim, houve a coleta, leitura, análise e sistematização de informações, estudos e legislações, específicas acerca dos temas. Por meio de questionário semi-estruturado buscou-se revelar as percepções dos estudantes sobre os resultados do projeto.

Percebeu-se, de forma geral, que a participação no Parlamento Jovem do TRE/PR permite que estudantes compreendam as atribuições e a importância do Poder Legislativo, em especial, da Câmara de Vereadores, bem como a forma de elaboração dos projetos de leis, 
requerimentos e função fiscalizatória dos vereadores. Tais fatores contribuem para o desenvolvimento da cidadania e do conhecimento sobre como se constitui uma democracia.

\section{EDUCAÇÃO PARA A DEMOCRACIA: DESAFIOS E POSSIBILIDADES}

A política entendida como a arte de negociar, refletir e ponderar tem como objetivo atender as necessidades do grupo, sem privilegiar um ou outro lado, buscando sempre que possível o equilíbrio. Como afirma a filósofa alemã Hannah Arendt (2010), a política é uma importante ferramenta na busca da felicidade do indivíduo e da sociedade. Nessa perspectiva, as pessoas são seres políticos, pois fazem uso da política para mediar as decisões, harmonizar as relações e atender aos objetivos propostos.

Existem pelo mundo diferentes regimes políticos, desde os mais democráticos e abertos, como também aqueles mais fechados à participação popular. Nestes últimos, a população não tem qualquer possibilidade de participação, discussão ou mesmo de questionamento, sendo proibido não somente o debate de ideias, mas também a veiculação de determinadas informações. Dessa maneira, a população se ausenta das decisões políticas, pois se apresenta totalmente destituída de informações e conhecimentos. São exemplos desse último tipo os governos tiranos, oligárquicos e ditatoriais.

A consolidação da democracia está atrelada, entre outros fatores, ao exercício da representatividade política. É por meio dessa representatividade que a vigência e permanência da democracia são permitidas nas sociedades contemporâneas. Para Alves (2013, p. 116):

[...] é possível considerar a democracia como direito fundamental de um povo específico, como um aspecto interno do direito à autodeterminação, em vista que, nos sistemas democráticos, a vontade do povo é o elemento central da autoridade do poder público e tem inegável caráter de fundamentalidade.

De acordo com Gramsci (2004), filósofo italiano, democracia estaria relacionada ao consenso e à participação. Por meio do consenso organizado e participativo é que se formaria uma vontade coletiva nacional. Para ele, democracia não se limita exclusivamente ao exercício do voto, mas teria uma concepção ampla e diretamente relacionada a uma relação equilibrada entre força e consenso. Define que os homens ao se aproximarem uns dos outros passam a entender-se e a desenvolver uma vontade social e coletiva, adequando os fatos econômicos da vida às suas vontades. 
Assim, muitos são os conceitos de democracia, no entanto, para o fim do presente trabalho, interessam os conceitos mais intimamente relacionados à participação política, que pode ser: direta, quando exercida pelo cidadão, normalmente em assembleia pública, mediante manifestação pessoal do indivíduo, que pode deliberar por si mesmo, sem intermédio de representantes, e não adotada no Brasil; semi-direta, exercida por meio de plebiscito ou referendo, ou mesmo no exercício de iniciativa de lei popular, prevista no art. 14, caput, incisos I, II e III da CF; ou representativa, de maneira que as decisões são deliberadas por representantes eleitos, para isso escolhidos, por indivíduos regularmente inscritos como eleitores de uma dada nação. Em relação a esta última modalidade Alves (2013, p.147) ensina que:

A técnica democrática e o princípio da maioria, nas democracias representativas,
impõe a agregação temporária das vontades individuais, em eleições periódicas, com
o objetivo de converter votos em mandatos, nas quais são constituídos
representantes, que terão legitimidade, durante determinado período de tempo, para
decidir em nome de um povo.

A participação política ativa compreende diversas atividades relativas a temas de interesse coletivo, tais como a associação em grupos, partidos políticos ou movimentos sociais para, por meio desses, reivindicar demandas e direitos específicos. No entanto, para exercer e reivindicar, é necessário que os cidadãos tenham o conhecimento de seus direitos e deveres, o que resulta num exercício mais qualificado da cidadania, cujo ápice se dá com a quitação eleitoral, que permite ao indivíduo o exercício dos direitos políticos ativos (votar) e passivos (ser votado). Nos termos do art. 14, da Constituição Federal, "a soberania popular será exercida pelo sufrágio universal e pelo voto direto e secreto, com valor igual para todos, e, nos termos da lei, [...]”. (BRASIL, 1988)

Faz-se relevante a advertência de Norberto Bobbio (1986), para quem a apatia política dos cidadãos compromete o futuro da democracia. Assim, para que uma comunidade exerça uma participação política efetiva e de qualidade é necessário que ela tenha conhecimentos, tanto dos direitos e deveres estabelecidos quanto do funcionamento das instituições políticas e poderes estatais, pois com base nisso poderá agir de forma relevante e adequada quanto aos rumos da vida pública. Dessa forma, o ambiente democrático pressupõe cidadãos conscientes, necessários para a construção de sociedades mais justas e igualitárias. 
Como parte disso, tem-se a eleição de representantes políticos para, entre outras funções, legislarem sobre assuntos de interesses sociais e coletivos.

A escolha dos representantes políticos pelos cidadãos é uma das condições necessárias para a existência e o bom funcionamento das democracias modernas. $\mathrm{O}$ voto direto, com igual valor para todos, nos termos do caput do art. 14 da CF, é uma das principais formas de participação política e exercício da cidadania. Dessa forma, a democracia requer a participação constante dos cidadãos e também o controle das ações dos representantes eleitos. O engajamento político dos cidadãos promove a inclusão e a justiça social através da ampliação e da efetivação dos direitos. (TEIXEIRA; SOUZA, 2014).

Como a cidadania, nos termos do direito constitucional positivo, não é uma condição natural, o letramento político deve existir para propiciar meios para que os cidadãos possam se apropriar, efetivamente, do seu lugar dentro de uma comunidade política, de forma criativa, crítica e autônoma.

De acordo com Barros e Martins (2016) pesquisas recentes indicam um baixo nível de letramento político da população em geral e especialmente dos jovens, não apenas no Brasil. Em estudo realizado, constatou-se que $62 \%$ dos entrevistados não conseguiam nomear os três poderes do Estado, o que indica um baixo nível de conhecimento, bem como elevado desinteresse pela política.

Por isso são necessárias ações sociais e políticas públicas de letramento político, que pode ser definido como "processo de apropriação de práticas, conhecimentos e valores para a manutenção e o aprimoramento da democracia” (COSSON, 2015, p.81).

O letramento político ou a educação para democracia visa desenvolver capacidades para que haja participações mais efetivas dos cidadãos na sociedade democrática. Ao tratar de educação para a democracia, a professora Maria Victória Bevenides (1996) afirma que deve haver o reconhecimento de que não há desenvolvimento exclusivamente no campo econômico, sem concomitante desenvolvimento social e político, por isso a questão da educação política torna-se de fundamental importância, e acrescenta que:

Educação é aqui entendida, basicamente, como a formação do ser humano para desenvolver suas potencialidades de conhecimento, de julgamento e de escolha para viver conscientemente em sociedade, o que inclui também a noção de que o processo educacional, em si, contribui tanto para conservar quanto para mudar valores, crenças, mentalidades, costumes e práticas. (BEVENIDES, 1996, p.225) 
Entende-se que a apropriação dessas capacidades pode ocorrer no ambiente escolar, por meio do conteúdo curricular ministrados nas aulas ou de projetos que envolvam a comunidade escolar e possibilitem a aquisição de conhecimentos, habilidades e valores democráticos.

\begin{abstract}
Educar politicamente para a cidadania é, principalmente, educar um sujeito participativo para ser um sujeito crítico, no sentido de co-participante da democracia. Essa é a verdadeira educação para uma nova cidadania, que é uma postura que precisa ser estimulada. Os direitos e deveres civis e políticos, devem ser trabalhados por meio de valores éticos. É necessário compatibilizar cidadania, política e diversidade, através de princípios éticos. Educar é uma ação que propõe a convivência social, a cidadania e a tomada de consciência política, fazendo de cada sujeito um autor de transformação social (MACEDO et al, 2013, p.3)
\end{abstract}

Considera-se que experiências práticas de exercício da cidadania possibilitam aos jovens aprendizados e concepções importantes sobre a democracia e seus aspectos.

Dessa forma, observa-se a relevância de ações educacionais que desenvolvam o letramento político. Neste contexto, acredita-se que a escola é também um dos espaços onde se pode aprender sobre cidadania, democracia e participação consciente. Para Arroyo (2002 p.79):

[...] a luta pela cidadania, pelo legítimo, pelos direitos, é o espaço pedagógico onde se dá o verdadeiro processo de formação e constituição do cidadão. A educação não é uma precondição da democracia e da participação, mas é parte, fruto e expressão do processo de sua constituição.

A escola é umas das instituições que mais influencia a sociedade, e que tem entre suas funções promover o desenvolvimento pleno do cidadão, formando-o para resolver necessidades individuais e coletivas. Assim, a escola tem o seu papel para a construção de uma sociedade democrática, mais justa e humana. Para Cavalcanti (2002, p.40) "a escola pode organizar ações para a formação da cidadania democrática ativa, com direitos amplos criados e recriados num processo histórico, social, econômico, cultural".

De acordo com Delors (2003, p.62) "a educação para a cidadania constitui um conjunto complexo que abraça, ao mesmo tempo, a adesão a valores, a aquisição de conhecimentos e a aprendizagem de práticas na vida pública”.

A capacidade de participar politicamente da sociedade não é inata, mas algo que precisa ser desenvolvido, e para que se aprenda, é preciso também ser ensinada. Esse seria o 
papel da educação para a cidadania, um meio de preparo para a participação política ativa, desenvolvendo a capacidade de opinar, discutir, questionar, intervir e participar nas decisões que afetam a vida da sociedade, seja por deliberação semidireta ou representativa.

\section{O PROJETO PARLAMENTO JOVEM DO TRE/PR E SEUS OBJETIVOS}

Segundo pesquisa de Rildo Cosson (2009), vários países democráticos apresentam alguma forma de simulação de seu processo eleitoral voltado para estudantes, sendo exemplos o Parlamento Jovem da Catalunha - Espanha, Finlândia, Índia, Nova Zelândia, entre outros. No Brasil, câmaras municipais, assembleias legislativas e a Câmara Federal desenvolvem programas de simulações parlamentares para o público escolar. O mesmo autor acrescenta que por meio dessa atividade abre-se a discussão para questões que permeiam a vida em sociedade e leva-se os estudantes a pensarem em propostas para solucioná-las.

Os propósitos comuns dessas e de várias outras simulações parlamentares são aprofundar os conhecimentos sobre o funcionamento do Legislativo, oferecer um canal de expressão e desenvolver o interesse pela participação política como instrumentos de ampliação da cultura democrática entre os jovens. (COSSON, 2009, p.2)

Tais iniciativas visam desenvolver conhecimentos e práticas de cidadania, pois ao conhecer as etapas de um processo eleitoral, o exercício do voto, a produção de projetos de leis, pedidos de informações e requerimentos, além da participação em comissões, os alunos poderão perceber a importância dessas garantias numa sociedade democrática. Dessa forma, desenvolvem-se as competências sociais dos estudantes, levando-os a refletir sobre as possibilidades de participação política.

Segundo documento (2019) do Tribunal Regional Eleitoral do Paraná, o projeto Parlamento Jovem tem a intenção de promover a educação política entre estudantes, estimulando-os ao exercício da cidadania e do voto responsável. Tem como objetivos estimular o envolvimento de adolescentes e jovens nas diferentes esferas de organização social, incluindo a participação nos organismos escolares de representação estudantil, esclarecer acerca da importância, da finalidade e das responsabilidades do exercício do voto e 
incentivar o alistamento eleitoral dos jovens a partir dos 16 anos. Como público-alvo tem estudantes de 10 a 17 anos.

A iniciativa surgiu do Colégio de Dirigentes de Escolas Judiciárias Eleitorais e visa despertar a consciência cívica nos estudantes regularmente matriculados na rede de ensino pública a privada. Nesse contexto, o TRE-PR realiza um processo eleitoral, com várias etapas, entre os alunos dos estabelecimentos de ensino participantes do projeto.

Os principais envolvidos são a Justiça Eleitoral por meio de suas Zonas Eleitorais, as Câmaras Municipais e as Escolas.

Dentro do projeto, o TRE-PR tem como suas atribuições ofertar assessoria de conteúdos básicos relacionados à política, ao processo eleitoral e à cidadania; disponibilizar os recursos materiais necessários para a realização das eleições nas escolas, como urnas, cartazes, folderes, entre outros; confeccionar título de eleitor específico para a participação no projeto com o nome de cada aluno votante conforme relação encaminhada pelas escolas; fornecer treinamento para os alunos que atuarão como mesários no dia da eleição; preparar as urnas eletrônicas parametrizadas com os dados dos candidatos e votantes para a eleição em cada escola.

As escolas participantes devem indicar um ou mais de seus profissionais para coordenar o projeto, sendo que este coordenador deverá apresentar o projeto aos estudantes e a outros profissionais da escola; devem também encaminhar às Zonas Eleitorais a relação dos estudantes que serão eleitores e também dos que foram escolhidos como candidatos por meio das convenções partidárias. Acompanharão as campanhas partidárias, orientando e propondo atividades; auxiliarão a organização da eleição indicando os mesários, organizando os espaços para instalação das urnas e seções, auxiliarão os estudantes na escolha dos partidos ao qual se filiarão; organizarão as convenções partidárias na elaboração das propostas. Organizarão, em parceria com o TRE/PR, a diplomação dos eleitos e as visitas à Câmara Municipal.

As Câmaras Municipais devem organizar datas para a visita dos estudantes às suas dependências; auxiliar na organização da cerimônia de posse dos estudantes eleitos; planejar e executar a participação dos vereadores mirins/jovens na atuação parlamentar por um ou dois anos, dependendo do que for estabelecido no Projeto.

De acordo com o Guia do Professor - Projeto Parlamento Jovem (2019), documento elaborado pelo TRE/PR, as escolas poderão propor a divisão dos alunos em 5 partidos que lhes são sugeridos, são eles: PVS (Partido Vida e Saúde), PLRD (Partido Liberdade, Respeito 
e Dignidade), PELICE (Partido do Esporte, Lazer e Integração da Comunidade Escolar), PEPC (Partido Educação, Profissionalização e Cultura) e PSPCV (Partido da Segurança Pública e Combate à Violência). Cada partido tem foco de discussão sobre os temas que lhe são relacionados.

O Partido Vida e Saúde discute temas relacionados à vida, ao autocuidado, à autoproteção, a prevenção do uso de drogas ilícitas na adolescência, à organização e ao acesso aos serviços de saúde para a prevenção da gravidez na adolescência, doenças sexualmente transmissíveis, à violência social, doméstica e entre adolescentes.

O Partido Liberdade, Respeito e Dignidade propõe discutir questões ligadas ao racismo, gênero, discriminação aos deficientes e minorias, questões indígenas, a situação dos adolescentes do meio rural, sexo na adolescência e exploração sexual infantil.

O Partido do Esporte, Lazer, e Integração da Comunidade Escolar incentiva a defesa do acesso as atividades esportivas e de lazer e a sua importância como fator de inclusão social, discute e elabora propostas para a valorização do adolescente na família e na comunidade, para a ocupação do tempo livre, para a aproximação e integração de adolescentes e docentes, harmonia escolar, manutenção, conservação e ampliação do espaço físico da escola e intercâmbio escolar

O Partido Educação, Profissionalização e Cultura debate temáticas como o trabalho infantil, o direito à profissionalização e à proteção no trabalho, empregabilidade, empreendedorismo juvenil, educação profissional, saúde e proteção do trabalhador, vocação do adolescente, sentido do trabalho para o adolescente, uso das tecnologias no aprendizado, na educação e na cultura, qualidade do ensino, diversidade cultural, inclusão escolar, atividades culturais e artísticas dentro e fora da escola.

O Partido da Segurança Pública e Combate à Violência tem como bandeira o combate à violência doméstica, à violência entre adolescentes. Propõe-se também discutir a redução da maioridade penal e inimputabilidade (exclusão da culpabilidade) do adolescente, à corrupção de menores e violência urbana.

Por meio desses partidos, o TRE/PR pretende possibilitar discussões a respeito de temas relevantes tanto para a convivência escolar quanto para a inserção do aluno em um contexto mais amplo de atuação cidadã. Com a discussão sobre os temas problematizados por cada um dos partidos têm-se uma análise aprofundada sobre questões que envolvem a vida dos cidadãos. Entretanto, no dia da eleição os alunos votam nos candidatos. 
A fase inicial do projeto dá-se com o encaminhamento pela Escola à Zona Eleitoral da planilha com o nome de todos os alunos que participarão do Projeto Parlamento Jovem para que possam ser emitidos os títulos eleitorais fictícios dos votantes. Após, a escola apresenta aos alunos os partidos políticos sugeridos pelo TRE e abre prazo para que os alunos se filiem. Deverão ser definidos os cargos de presidente, tesoureiro e secretário, dentre os filiados em cada partido. Estes com o auxílio do coordenador escolar deverão organizar as convenções partidárias para a escolha dos candidatos a vereadores mirins (no caso do ensino fundamental) e vereadores jovens (ensino médio). Como atividade pedagógica o TRE sugerese que os estudantes pesquisem de que forma os partidos reais organizam suas convenções, quem tem direito a voto, quais os critérios para ser candidato nas convenções, etc.

Após a escolha dos candidatos em convenção, inicia-se o período de campanha eleitoral que deve seguir regras preestabelecidas. O TRE propõe que as escolas incentivem atividades de propaganda eleitoral com cartazes, folderes, comícios, debates entre os candidatos, etc.

A equipe de servidores da Zona Eleitoral ficará responsável pelo treinamento dos mesários indicados pela Escola, os quais ficarão responsáveis pelo manuseio das urnas eletrônicas no dia da eleição.

A data marcada para eleição dos vereadores mirins ou jovens será organizada e coordenada pelos Cartórios Eleitorais com apoio e suporte da Escola e os alunos utilizarão como documento para votação o título fictício enviado pelo TRE, exclusivo para o pleito.

\section{A EXPERÎENCIA DO PARLAMENTO JOVEM NA CIDADE DE JACAREZINHO/PR}

A Justiça Eleitoral, em convênio com a Câmara Municipal de Jacarezinho - PR e três instituições de ensino deste município, iniciou em fevereiro de 2019, o Projeto Parlamento Jovem do TRE/PR. Por meio da participação de estudantes do ensino fundamental e médio pretendeu-se promover cidadania e despertar a consciência dos estudantes para questões relevantes da vida em comunidade.

Dentro desse processo houve a organização de eleições nas três instituições de ensino participantes, visando oferecer aos estudantes uma real experiência de todo o processo 
eleitoral. Objetivou-se demonstrar qual o percurso necessário para se alcançar o resultado das eleições municipais, desde seu início, com a filiação partidária, até a diplomação e posse dos candidatos eleitos.

Para iniciar o projeto o Cartório Eleitoral de Jacarezinho enviou ofícios a todas as Escolas e Colégios Estaduais do município, convidando-as para a participação. Houve a adesão de três instituições, a saber: a) Colégio Estadual José Pavan, com aproximadamente 180 alunos votantes; b) Colégio Estadual Anésio de Almeida Leite, com aproximadamente 180 alunos votantes; c) Instituto Federal do Paraná, com aproximadamente 470 alunos votantes.

Assim, o projeto foi elaborado de forma que houvesse a eleição de três candidatos, mais os suplentes, por Colégio. Totalizando nove vereadores mirins/jovens, sendo mirins aqueles eleitos até 13 anos, e jovens aqueles entre 13 e 17 anos, ou maiores, caso ainda estivessem cursando o ensino médio, já que, considerando a participação do Instituto Federal do Paraná, cujos cursos do ensino médio podem durar quatro anos, houve alunos maiores de idade candidatos, sendo um deles, inclusive, eleito para o cargo de vereador.

Antes de o projeto iniciar-se no âmbito escolar, promoveram-se reuniões com os gestores das instituições de ensino participantes, servidores da Zona Eleitoral de Jacarezinho e Juiz Eleitoral, para ajustes no formato e adaptações julgadas necessárias. Após iniciado, a equipe do Cartório Eleitoral (servidores, estagiário e Juiz) esteve por diversas vezes nos Colégios prestando assessorias nas etapas do processo, dentre elas: apresentação dos partidos disponíveis, abertura do período de filiação pelos alunos, escolha da diretoria dos partidos, convenção partidária para escolha dos candidatos, propaganda eleitoral, treinamento de mesários, dia da eleição, diplomação dos eleitos.

Houve, também, visitas realizadas pela Câmara Municipal por meio de dois vereadores e do procurador jurídico, para explicar aos alunos as atribuições do vereador, o processo de elaboração de projetos de leis e o regimento interno da Câmara. O Juiz Eleitoral visitou os três Colégios e fez explanações aos alunos sobre a importância do voto, da democracia e da participação política.

Durante o desenvolvimento dos trabalhos, a equipe do Cartório Eleitoral providenciou uma visita guiada aos três prédios dos Poderes do Município de Jacarezinho. Dessa forma, os trinta e dois candidatos ao pleito e mais alguns professores visitaram a Câmara Municipal, a Prefeitura e o Fórum Eleitoral para terem uma noção básica das funções, 
composição e trabalhos desenvolvidos, além de lições sobre a divisão de poderes no Brasil, por meio de noções básicas acerca da função de cada um deles, tudo ministrado pelos servidores da Justiça da 24ª Zona Eleitoral de Jacarezinho/PR.

De grande contribuição para o sucesso do Projeto e para promoção de inclusão e prática da igualdade material, foi a participação da Escola de Educação Especial Professor Carlos Neufert, também de Jacarezinho-PR. Considerando que um dos alunos candidatos é deficiente visual, esta escola providenciou, a pedido do Cartório Eleitoral, a impressão de santinhos de propaganda eleitoral escritos em braille, além de imprimir, de forma gratuita, o diploma em braille deste aluno que foi eleito como suplente. Durante a visita guiada, na qual este aluno participou, os servidores do Cartório Eleitoral tomaram cuidado de descrever oralmente os ambientes em que este estudante se encontrava, falando sobre as dimensões do local, os objetos que ali estavam, e para qual fim o local era utilizado.

As eleições ocorreram nos Colégios e Instituto Federal no dia 07 de junho de 2019, com a utilização de urnas eletrônicas. O Tribunal Regional Eleitoral do Paraná providenciou títulos de eleitor fictícios para todos os alunos votantes. Foram emitidos 980 títulos, mas 648 alunos votaram, considerando transferências e abstenções no dia da votação.

Superadas tantas etapas, aconteceu a diplomação dos estudantes eleitos em cerimônia realizada em cada colégio, com a participação dos demais alunos e professores. Por meio desse ato administrativo, a Justiça Eleitoral atestou perante a comunidade escolar que os vereadores mirins/jovens eleitos estão aptos e legitimados à representação dos seus eleitores.

Ainda como parte desta pesquisa, pretendeu-se verificar as percepções dos alunos quanto às contribuições de aprendizagens proporcionadas pela participação no projeto Parlamento Jovem, bem como a aplicação dos conteúdos apreendidos em suas intervenções solidárias na comunidade.

Dessa forma, 16 alunos participaram dessa fase da pesquisa, os quais foram candidatos nos três colégios. Mediante Termo de Consentimento de participação em pesquisa, receberam um questionário semiestruturado que versava sobre aspectos da participação no projeto. Os estudantes respondentes foram identificados, para este estudo, com a letra $\mathrm{E}$, seguida de um número diferenciador.

O foco das perguntas foi compreender as percepções acerca das contribuições do projeto Parlamento Jovem, sob a ótica daqueles que foram seus participantes. 
Nas respostas da primeira pergunta: "O que você aprendeu até o momento com a sua participação no projeto?” percebe-se que houve menções a apreensão de conhecimentos quanto à estrutura dos poderes estatais e sobre o desenvolvimento do processo eleitoral:

Aprendi sobre os três poderes e a importância do voto. (E12)

Sobre como funciona uma eleição, como é o funcionamento de uma câmara (E13).

Acredito que compreendi muito melhor sobre o funcionamento da máquina pública e meus direitos e deveres como cidadão. (E10)

[...] a função dos poderes e de cada cargo eleitoral, aprendi sobre o processo e a burocracia da eleição e também sobre a fiscalização e o nosso papel como cidadão contra a corrupção. (E9)

Aprendi sobre o funcionamento de cada setor da câmara dos vereadores e a maneira correta de se fazer um projeto e enviar para o prefeito. (E8)

Aprendi que não é simples um processo eleitoral, pelo contrário é um processo rígido e burocrático. (E2)

[...] que esse projeto é muito importante, pois os jovens não fazem idéia de como funciona a política de nosso país. Eu mesmo não sabia de muitas coisas sobre o sistema. (E1)

Considera-se que o desenvolvimento desses conhecimentos é importante para uma participação política plena e consciente. Alguns alunos também mencionaram como resultado a conscientização sobre aspectos do voto e a observância quanto à qualidade na escolha dos candidatos.

Aprendi com o projeto sobre a importância do voto consciente (E9)

[...] que quem nós escolhemos para representar como vereadores tem que ser pessoas de bom caráter (E5)

Também possibilitou reflexões sobre qual o papel que o estudante pode exercer para a construção de uma sociedade mais solidária e democrática:

Aprendi que com esse projeto posso tentar ajudar mais nosso bairro. (E6)

Que desde já nós podemos fazer a diferença, não precisamos pegar uma certa idade para fazer o melhor para nosso Brasil. (E11) 
Foi possível observar a percepção de alguns estudantes quanto a contribuições no desenvolvimento pessoal, reforçadas durante o projeto:

Aprendi a ser mais educado e respeitoso com os outros. (E3)

Aprendi a ser mais participativo e com o projeto aprendi como funciona a política. (E7)

Essas falas parecem revelar que a participação no projeto ampliou a percepção dos estudantes sobre o processo eleitoral e suas responsabilidades como cidadãos do mundo em que fazem parte.

Outro questionamento proposto aos alunos foi: $O$ que você espera de sua participação no projeto? Ao analisar as respostas verificou-se o desenvolvimento de uma consciência cidadã, observada no estímulo à capacidade de compreender e discutir os problemas comuns da sociedade:

Eu espero fazer várias coisas para a minha comunidade (E12)

Que seja bastante útil, que eu possa ajudar bastante minha comunidade com alguns projetos. Um projeto que tenho em mente é colocar latas de lixo nas ruas, porque aqui no meu bairro não tem nenhuma e as pessoas acabam jogando o lixo no chão. (E7)

Estarei nesses 6 meses de mandado defendendo os direitos de toda comunidade escolar do município. (E10)

Com toda certeza, na verdade, eu pretendo ajudar com todo e qualquer recurso que estiver em meu alcance. (E9)

Essa consciência cidadã, pautada numa perspectiva emancipatória e transformadora, capacita o estudante ao exercício de juízos reflexivos sobre as relações humanas no contexto social:

Com a participação de todos a gente pode fazer algo melhor para o bairro. (E6)

Que eu possa fazer a diferença, sim! (E11)

Espero contribuir para as escolas em geral, pois com a minha candidatura sinto que farei a diferença. (E2) 
Houve, também, falas que demonstram o despertar do desejo de participação em processo eleitorais reais no futuro. Isso significa o entendimento de que é possível participar da vida social como cidadão comum ou como detentor de mandato político. Enquanto governado, necessário ter conhecimento de seus direitos e deveres e como governante, detentor de mandato, observar a qualidade de sua atuação política:

Acredito que minha candidatura ao Parlamento Jovem contribuirá e muito para a participação em uma eleição real. (E10)

Eu espero aprender mais sobre a política na prática e ter um bom desempenho no meu cargo. (E9)

As falas acima revelam a compreensão de que por meio da atuação política é possível contribuir para melhoria nas relações sociais. Vislumbra-se com a participação no projeto criar bons valores e promover, pela perspectiva da reflexão, novas formas de atuação dos jovens na política.

Assim, o letramento político proporcionado durante o projeto pode ser capaz de proporcionar processos de empoderamento, em que estudantes percebam-se como participantes ativos de sua comunidade, que reflitam sobre suas posturas e a necessidade de revê-las, que se sintam responsáveis por suas decisões políticas.

\section{CONCLUSÃO}

Mais do que escolher um candidato e votar na urna eletrônica, o Projeto Parlamento Jovem do TRE/PR pretende desenvolver nos alunos novas formas de participação, de discussão e envolvimento político. Na implementação do projeto em Jacarezinho/PR foi possível perceber, entre outras coisas, o direcionamento de preocupações com o que é público, coletivo, de modo que não houve por parte dos estudantes reivindicação de benefícios individuais, mas o interesse em elaborar propostas de cunho social. Espera-se que esses alunos construam participações eleitorais futuras de maior qualidade, que valorizem o processo eleitoral como algo importante para a democracia.

O estudante ao escolher o partido político em que se filiou teve a oportunidade de refletir como os interesses organizados podem proporcionar o debate de relevantes questões 
públicas. Os processos educativos podem oferecer aos seus participantes a oportunidade de se apropriar de conhecimentos, práticas e valores democráticos, constituindo-se, dessa forma, o letramento político. Portanto, ao se promover o letramento político abre-se perspectivas para revigorar a cultura política.

Junto a esses conhecimentos sobre o processo político, os estudantes reconheceram durante o Parlamento Jovem o impacto das suas ações sobre os outros; a necessidade de resolver os conflitos por meio do debate, da cooperação e da ação coletiva; a importância de respeitar a posição do outro e a existência fundamental de regras comuns a todos nas relações sociais. Em outras palavras, eles acabam absorvendo os valores de liberdade, equidade, justiça social e solidariedade que sustentam uma sociedade democrática.

\section{REFERÊNCIAS}

ALVES, F. de B. Constituição e participação popular. A construção histórico-discursiva do conteúdo jurídico-político da democracia como direito fundamental. Curitiba: Juruá, 2013.

ARENDT, H. A vida do espírito: o pensar, o querer, o julgar. Trad. César Augusto Ramos de Almeida, Antônio Abranches e Helena Franco Martins. $2^{a}$ Edição. Rio de Janeiro: Civilização Brasileira, 2010.

ARROYO, M. G. Educação e exclusão da cidadania. In: BUFFA, E. (org.). Educação e cidadania: quem educa o cidadão? São Paulo: Cortez, 2002.

BARROS, A. T. de; MARTINS, L. M. Impactos do Parlamento Jovem Brasileiro na motivação e participação política partidária dos egressos. Revista Debates, 10(2), 95-120. 2016. Disponível em: http://bibliotecadigital.tse.jus.br/xmlui/handle/bdtse/2487 . Acesso em 28 ago.2019.

BRASIL. Constituição (1988). Constituição da República Federativa do Brasil: promulgada em 5 de outubro de 1988. Disponível em: http://www.planalto.gov.br/ccivil_03/constituicao/constituicaocompilado.htm. Acesso em 10 ago.2019.

BENEVIDES, M. V. M. Educação para a democracia. Lua Nova, São Paulo, n. 38, p.223237, 1996.

BOBBIO, N. O Futuro da Democracia. São Paulo: Ed. Paz e Terra, 1986.

CAVAlCANTI, L. S. Geografia, Escola e Construção de Conhecimentos. Campinas: Papirus, 2002. 
COSSON, R. Letramento político no legislativo: a experiência do Programa Estágio Visita. 2015. Tese (Doutorado em Educação) - Faculdade de Educação, Universidade Federal de Minas Gerais, Minas Gerais, 2015.

COSSON, R. Dois modelos de parlamento jovem: uma leitura de seu funcionamento como letramento político. Estudos Legislativos, v. 3, 2009, p. 34-45

DELORS, J. Educação: um tesouro a descobrir. 2ed. São Paulo: Cortez, 2003.

GRAMSCI, A. Cadernos do Cárcere: Introdução ao Estado da Filosofia de Beneditto Croce, v. 1, Rio de Janeiro: Civilização Brasileira, 2004.

MACEDO, M. do C. F.; TELLES, B. M.; SILVESTRE, A. C. F.; FRANCO, M. F. Educação Cidadã: desafio interdisciplinar. Interdisciplinaridade / Grupo de Estudos e Pesquisa em Interdisciplinaridade (GEPI) - Educação: Currículo - Linha de Pesquisa: Interdisciplinaridade - v. 1, n. 3 (out. 2013) - São Paulo: PUCSP, 2013. Periodicidade semestral. p. 50-62.

TEIXEIRA, A. E.; SOUZA, R. S. R. A formação política no Parlamento Jovem de Minas. Relatório de atividades da Escola do Legislativo. Assembleia Legislativa do Estado de Minas Gerais, Escola do Legislativo, Belo Horizonte, 2014. p.21-26.

TRIBUNAL REGIONAL ELEITORAL DO PARANÁ. Escola Judiciária Eleitoral do Paraná. Parlamento Jovem no Paraná. 2019a. Disponível em: http://www.tre-pr.jus.br/o-tre/escolajudiciaria-eleitoral/projetos/tribunal-eleitoral-jovem. Acesso em 28 ago.2019.

Escola Judiciária Eleitoral do Paraná. Projeto Parlamento Jovem: Guia do Professor. Curitiba. 2019b. Disponível em: http://www.tre-pr.jus.br/o-tre/escola-judiciariaeleitoral/projetos/tribunal-eleitoral-jovem. Acesso em 28 ago.2019. 